\title{
Poker Flat MST radar observations of high latitude neutral winds at the mesopause during and after solar proton events
}

\author{
R. M. Johnson* and J. G. Luhmannt \\ * Space Physics Research Laboratory, University of Michigan, Ann Arbor, MI 48109, U.S.A.; \\ $\dagger$ Institute of Geophysics and Planetary Physics, UCLA Los Angeles, CA 90024, U.S.A.
}

(Received in final form 4 September 1992 ; accepted 1 October 1992)

\begin{abstract}
Observations with the Poker Flat, Alaska, MST radar during and after solar proton events in 1982 and 1984 suggest that winds in the altitude range of $\sim 80-90 \mathrm{~km}$ were altered as a consequence of the influx of energetic charged particles and large electric fields at high latitudes. The atmospheric changes accompanying these events appear to result in a reduction of the semidiurnal tide and an enhancement in the diurnal tide. It is suggested that these changes could result from the alteration of the local tidal heating distribution produced by the particle precipitation, either through changes in the local ozone distribution or as a result of mesospheric Joule heating.
\end{abstract}

\section{INTRODUCTION}

The response of the high-latitude upper atmosphere to short-term changes in magnetospheric forcing is strongest at heights above about $100 \mathrm{~km}$, in or above the lower thermosphere (JoHnson and LuHMANN, 1988). Below this altitude, neutral dynamics in the auroral zone upper mesosphere are dominated by the influences of lower-atmospheric processes, such as the generation and upward propagation of atmospheric tides due to ozone and water vapor absorption at UV and infra-red wavelengths, the deposition of gravitywave momentum at critical levels, and turbulent dissipation (Holton, 1975). However, several studies have indicated weak statistical relationships below $100 \mathrm{~km}$ between tidal amplitudes and/or gravity-wave intensities and magnetospheric forcing (MANSON and MEeK, 1986; Price and JACKA, 1991; PrICe et al., 1991). In the high-latitude lower thermosphere, diurnal and semidiurnal tides are also produced in situ through absorption of solar radiation at UV and EUV wavelengths. The much enhanced $E$-region ionization density relative to the $D$-region, in combination with the magnetospheric convection electric field (which maps down geomagnetic field lines to the high-latitude regions) allows ion-neutral coupling to have a much greater influence on auroral zone neutral dynamics in the lower thermosphere than below. Several studies have shown that accelerated zonal and meridional flows as well as reductions in semidiurnal tidal amplitude are observed during intervals of enhanced magnetospheric input (WAND, 1983; JOHNSON, 1987; COGGER et al., 1985; JOHNSON and VIRDI, 1991; KILLEEN et al., 1992). Nevertheless, on occasion, sufficiently energetic particle precipitation can affect even the mesosphere, although the mechanisms and nature of the effects may differ from those observed in the lower thermosphere. Solar Proton Events (SPEs) which are characterized by extremely intense particle precipitation over large spatial regions and intense magnetospheric convection, are particularly likely to generate mesospheric effects.

During these events, the ionization at upper-mesospheric heights may reach sufficiently high levels that Joule heating competes with the contribution due to normal neutral heating from absorption of solar radiation (BANKs, 1979; RoBle et al., 1987). Additionally, another possible mechanism for altering the dynamics of the neutral gas may become effective as a result of the energy deposited in the stratosphere and mesosphere by unusually intense precipitation of energetic particles, including solar protons. The ionization produced by these particles and their secondaries gives rise to local ionization and chemical reactions (THORNe, 1980), as well as changes in the densities of photochemically active atmospheric constituents (MAEDA and Aikin, 1968; Crutzen and SOlomon, 1980; SOLOMON et al., 1981) which are important in the production of tides in the middle atmosphere (PARK and London, 1974).

In this paper, observations of high-latitude uppermesospheric neutral winds obtained by the Poker Flat MST radar during two SPEs, on 13 July 1982 and 26 April 1984, are presented and examined for evidence of a response to high-latitude forcing. The observations are then discussed in relation to the possible mechanisms by which such extreme events can influence neutral gas dynamics, including upper-mesospheric Joule heating and precipitation-related photochemistry changes. 


\section{Observations of ozone depletions and Joule heating}

During the 13 July 1982 SPE, several instruments were in operation which could observe not only the ozone depletion, but also the precipitating particle flux and polar cap electric fields during the event. The NOAA-6 satellite measured incoming energetic proton fluxcs, while Dynamics Explorer-2 measured precipitating electron spectra, ion drift velocities and electron, ion, and neutral temperatures along the satellite track (RoBLE et al., 1987). The DE measurements showed that the energetic particle flux during the event abruptly decreased equatorward of $56^{\circ} \mathrm{N}$ latitude.

Observations of mesospheric ozone were made continuously during this event with both Solar Mesosphere Explorer (SME) and the Nimbus 7 satellites (ThOMAS et al., 1983; MCPeTERs and JACKMAN, 1985). Both SME and Nimbus 7 detected large ozone depletions in the mesosphere with a duration that is consistent with the dominance of the odd-hydrogen removal process during events characterized by soft precipitating particle spectra (FREDERICK, 1976). On the descending phase of its orbit, SME detected a maximum ozone depletion of $70 \%$ al $65^{\circ}$ and $78 \mathrm{~km}$ near 3 LT, while during the ascending phase near $15 \mathrm{LT}$, a depletion of $30 \%$ was found at $85 \mathrm{~km}$ and $65^{\circ}$ (Thomas et al., 1983). Nimbus 7, traveling in a local noon, midnight orbit, observed a $28 \%$ depletion at $55 \mathrm{~km}$ and high solar zenith angle, corresponding to a latitude of $72^{\circ} \mathrm{N}$, while at local noon observations at the same latitude showed only a $5 \%$ reduction in ozone normal concentrations at $55 \mathrm{~km}$ (MCPETERS and JACKMAN, 1985).

In Fig. 1, the observations of ozone depletion made with these two instruments at $\approx 70^{\circ} \mathrm{N}$ and at high and low solar zenith angle are shown together. The solid curves give the average mixing ratio of ozone per unit volume measured in July 1982 with SME. The dashed curve indicates observations by SME during the SPE on 13 July (Thomas et al., 1983). The thin curve shows the Nimbus 7 measurements during the maximum interval of proton precipitation (MCPETERS and $\mathbf{J}_{\mathrm{ACK}}$ MAN, 1985), to be compared with the normal ozone mixing ratios observed by Nimbus 7 (dash-dotted curves). The disagreement in the ozone depletions obtained by the two instruments at $55 \mathrm{~km}$ has been attributed to a local time effect.

KOBLE et al. (1987) have calculated the spatial distributions of Joule heating for the 13 July 1982 SPE in the mesosphere and the thermosphere from observations made with the DE-2 satellite on one orbit over the polar cap and coincident NOAA-6 satellite observations. They found that Joule heating rates exceeded solar heating rates, above $73 \mathrm{~km}$ in the eve-
July 13,1982 Ozone Depletion
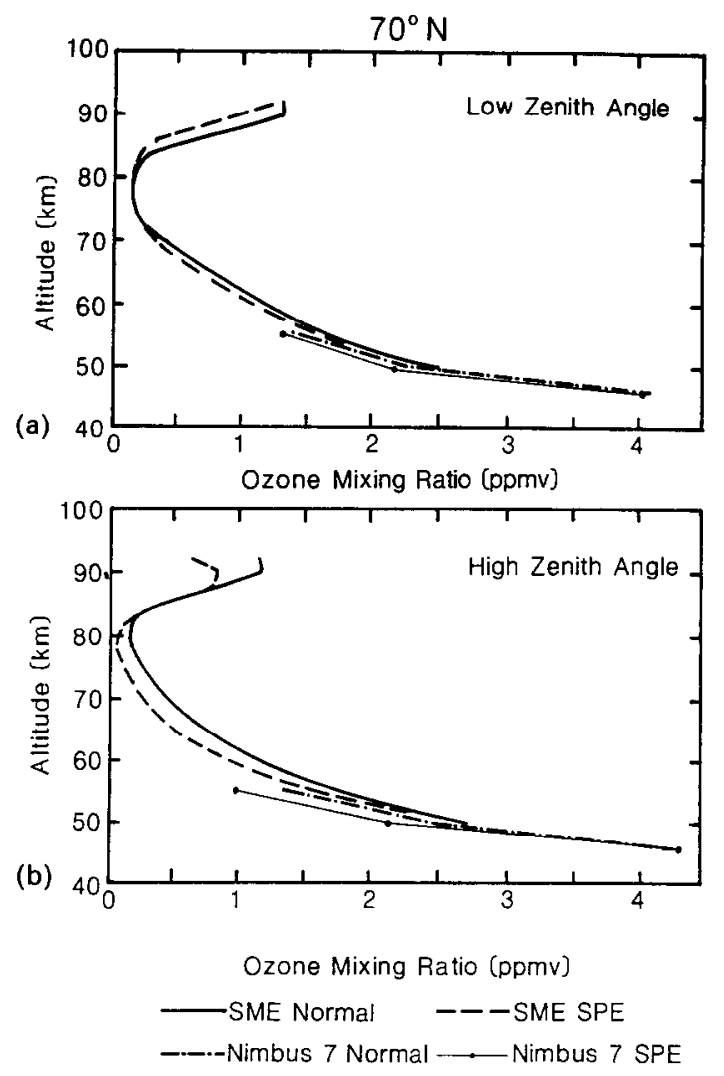

Fig. 1. Ozone mixing ratios in ppmv observed by SME and Nimbus 7 during the 13 July 1982 SPE at (a) low and (b) high solar zenith angles. These observations correspond to a latitude of $\approx 70^{\circ} \mathrm{N}$. The solid curves show the average mixing ratio of ozone measured by SME during July of 1982, while dashed curves are the SME observations made during the SPE. Normal ozone mixing ratios measured by Nimbus 7 are shown with a dash-dotted curve, while those obtained during the SPE are indicated by the thin solid curve with dots.

ning auroral oval and above $85 \mathrm{~km}$ in the polar cap, for this orbit during the peak of the geomagnetic storm while solar protons were still providing intense $D$-region ionization. Figure 2 compares the calculated Joule heating rates in the region of most intense electric fields with normal ozone heating rates in the mesosphere (after RoBLE et al., 1987). The most intense particle bombardment, producing greater than 3000 ion pairs $\mathrm{cm}^{-3} \mathrm{~s}^{-1}$, lasted about $8 \mathrm{~h}$, from 16 to $24 \mathrm{UT}$, although less energetic proton precipitation produced ionization enhancements from about $4 \mathrm{UT}$ on the 13th through 6 UT on the 14th at $80 \mathrm{~km}$ (MCPETERS and JACKMAN, 1985). The perpendicular (to B) electric fields measured by DE-2 on this orbit 
Heating Rate Comparison

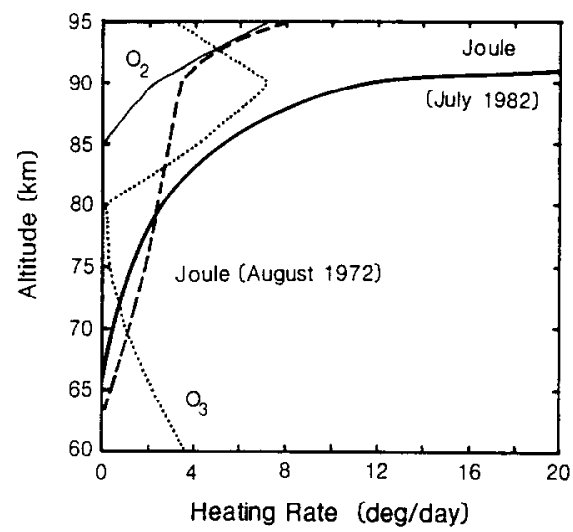

Fig. 2. Joule heating rates calculated by RoBLE et al. (1985) for a DE-2 orbit during the most intense period of particle precipitation of the 13 July 1982 SPE. For comparison, normal mesospheric ozone and molecular oxygen heating rates calculated for the summer hemisphere using the model of GARCIA and SOLOMON (1983) are also shown (after ROBLE et al., 1985).

maximized at about $190 \mathrm{mV} / \mathrm{m}$ in the evening sector at about $65^{\circ} \mathrm{N}$, but were generally elevated across the polar cap to $\approx 50 \mathrm{mV} / \mathrm{m}$. Time dependent Joule heating rates were not calculated for the event. However, since $K_{p}$ equalled or exceeded $8^{+}$for $12 \mathrm{~h}$, coincident with the most intense interval of particle precipitation, it is reasonable to assume that the Joule hcating rate during this interval significantly exceeded normal levels at mesospheric heights for an extended period of time during the SPE.

In Fig. 3, the ozone mixing ratio observed by SME

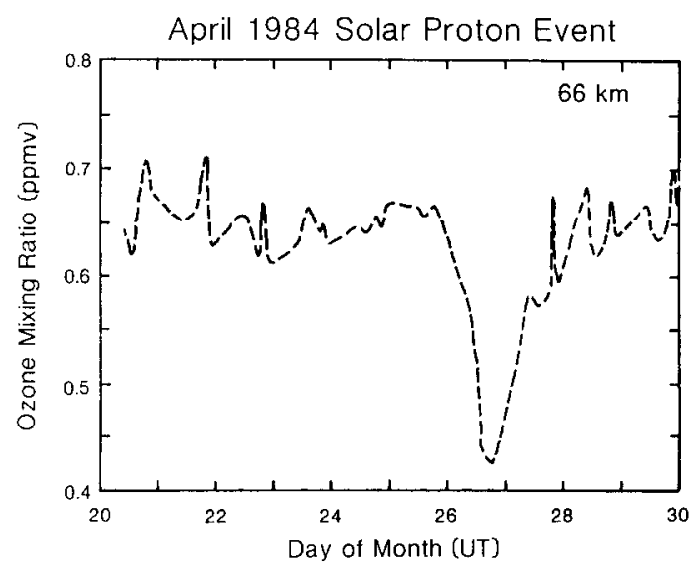

Fig. 3. Ozone mixing ratio in ppmv observed by SME during the interval of the April 1984 SPE at high solar zenith angle on the dayside. Time is shown in UT days. Data provided by R. J. Thomas. (provided by R. Thomas) during the 26 April 1984 SPE at $0.1 \mathrm{mb}(\approx 66 \mathrm{~km})$ and high solar zenith angle on the dayside of the satellite's orbit is shown. An ozone depletion of about $30 \%$ was observed at $80^{\circ} \mathrm{N}$. This depletion is significantly larger than that observed at this latitude and height on the dayside during the 13 July 1982 SPE. In Fig. 4, contours of constant ozone depletion level measured by SME are indicated for both the April 1984 (provided by R. Thomas) and the July 1982 SPEs (after THOMAS et al., 1983). The ozone depletion produced by the April event was more widespread in the polar regions, and reached larger values at lower altitudes than during the July event, although the July event had the largest ozone depletions in the upper mesosphere at high solar zenith angle. This difference in the distribution of ozone depletion is due to the dependence of the ozone removal process on both the solar zenith angle and the precipitating particle energy spectrum. During
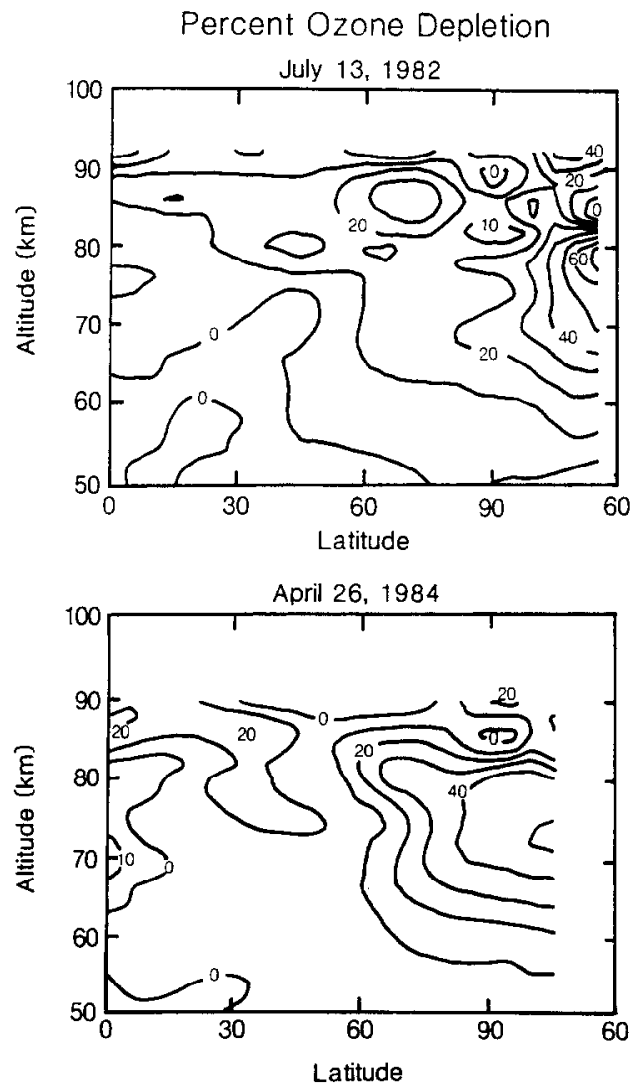

Fig. 4. Contour levels of constant ozone depletion level in percent vs altitude and latitude observed by SME during the April 1984 SPE (bottom) (provided by R. J. Thomas) and during the 13 July 1982 SPE (top) (after THOMAs et al., 1983). 
April, the solar zenith angle is higher at the same geographic latitude on the dayside than it is during summer months. As a result, the ozone depletion produced by the particle precipitation will have a proportionally larger effect to lower latitudes on the dayside since odd-hydrogen production through water vapor photolysis is reduced. Additionally, ozone depletion to lower altitudes during this event indicates a harder energy spectrum, allowing particle penctration to lower altitudes, than during the July 1982 event. Measurements of the Joule heating rate are not available for the April 1984 SPE.

The atmospheric effects of SPEs are therefore twofold in nature. Energetic proton precipitation produces enhanced ionization in the mesosphere and the stratosphere. This enhanced ionization, in the presence of large electric fields, allows Joule heating to provide an important source of neutral heating at upper-mesospheric heights and high latitudes. Friction between the ions, which are driven by the electric fields, and the neutrals also provides a source of momentum for the neutrals. Additionally, through a series of chemical reactions, the ionization causes a depletion of ozone in the middle atmosphere. This depletion reduces the neutral heating rate due to UV absorption by ozone in the upper stratosphere and mesosphere, dependent on the energy spectrum of the precipitating particles. Since absorption of UV by ozone in the middle atmosphere is the dominant source of mesospheric tides, and since the thermal response time of the atmosphere is slow, ozone depletions produced during SPEs have the potential for disrupting the normal dynamical behavior of the neutral gas for several days after the event (REAGAN et al., 1981).

\section{POKER FLAT MST RADAR OBSERVATIONS OF NEUTRAL WINDS}

The extreme variability of semidiurnal and diurnal tidal amplitudes and phases at upper-mesospheric and lower thermosphere heights has been pointed out numerous times in the literature (Fellous et al., 1975; BERNARD, 1981 ; MANSON et al., 1982). This variability has also been observed by CARTER and BALSLEY (1982), using the Poker Flat MST radar. A detailed analysis of data from this radar, showing that diurnal and semidiurnal tidal fluctuations in 3-yr of continuous summertime observations were strong, but highly variable in amplitude and phase was described by JoHNSON and LuHMANN (1985). In the course of analyzing the tidal amplitudes in the data set as a whole, one 3-day interval stood out because of its unusually consistent tidal behavior. This interval was characterized by large amplitude diurnal waves which showed little phase variation with altitude or time, and by significant semidiurnal amplitudes. The 13 July SPE and the ensuing geomagnetic storm, which continued through the UT day on the 14th, immediately preceded this 3-day interval. Because the operating mode of the radar was changed during the event, the time-series analyses of upper-mesospheric neutral winds presented by Johnson and LuHManN (1985) did not include the observations made during the 1982 SPE. These special observations are analyzed here, in conjunction with other observations made during the first three weeks of July 1982.

Observations made during a second intense SPF, which occurred in April, 1984, are also presented and discussed, although in less detail than the 13 July 1982 event. This event has been less thoroughly investigated for several reasons. Seasonal dependence is important because the altitude from which Poker Flat MST radar echoes are obtained depends sensitively on the time of year (BALSLEY et al., 1984). Thus data obtained during a different time of year will not typically be available at the same altitudes. Additionally, less observational data are available for this event. Even so, obscrvations arc presented in order to ascertain if the unusual behaviors exhibited following the 13 July 1982 event were coincidental, or related to a preceding interval of extreme magnetospheric forcing.

\section{July 1982 solar proton event}

Figure 5 shows the time histories of the observations made during the summer months of 1982 on one of the oblique receivers of the Poker Flat MST radar, in the $80-90 \mathrm{~km}$ altitude range. The receiver monitored the return signal from an azimuth of $64^{\circ} \mathrm{E}$ of geographic north, and so the radial velocities shown in this plot are positive in a roughly west-southwest direction. The main point this figure makes is the extreme variability of the neutral wind observations. On close inspection, one can find occasions when fluctuations of certain periods are apparently enhanced. This is particularly true of the semidiurnal component; of all the wave motions seen in these curves, the semidiurnal oscillation is the most consistently intense. For example, semidiurnal fluctuations are strong during the interval of the 6-11 June, but are particularly so on the 8 th and the 10th. Again on the 25th and 26th, semidiurnal oscillations are apparent, as they are during the interval from the 4th to the 7 th of July. There are also several intervals when the higher frequency oscillations are particularly coherent, for example, 13-14 June, and on 3 July. There 

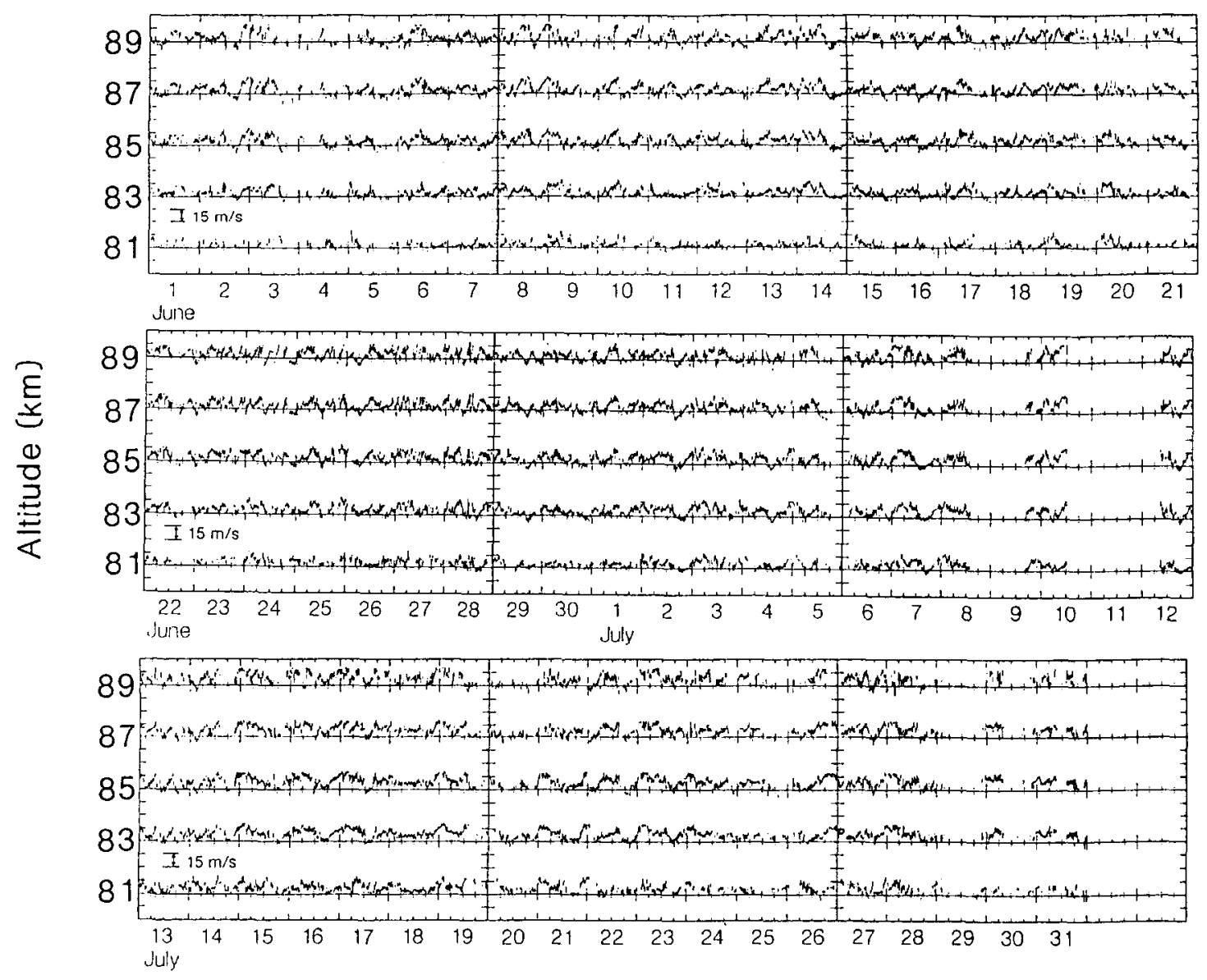

Fig. 5. Radial velocities in the $8090 \mathrm{~km}$ range on one of the oblique receivers of the Poker Flat, MST radar for the months of June and July 1982 . Velocities are positive in a west-southwest direction. Local time in days is indicated along the abscissa of each panel of the figure.

was only one interval, however, when a strong diurnal oscillation was present, essentially to the exclusion of other low-frequency components. This interval, which lasted for several consecutive days, occurred from about 21 LT on 14-17 July. It was followed by a roughly $24 \mathrm{~h}$ interval, mainly on the $18 \mathrm{th}$, when no low-frequency motions were apparent over the 80$90 \mathrm{~km}$ range at either the diurnal or the semidiurnal frequencies. No similar interval, devoid of all but high-frequency oscillations, was observed in the 1982 summer data shown in Fig. 7; indeed, this behavior is unique to the entire 3-yr data set. Following this $24 \mathrm{~h}$ interval, the radial velocities on the 19th and 20th showed the presence of a semidiurnal oscillation again.

In Fig. 6, the observations during the 12-18 July interval are shown in greater detail. Radar observations began again on the 12th after a period of roughly $48 \mathrm{~h}$ when the facility was not in operation. (In fact, except for an approximately $24 \mathrm{~h}$ interval from 9 to $10 \mathrm{July}$, the radar did not obtain measurements for 4 days prior to 12 July.) The most intense energetic proton precipitation occurred during the interval indicated by the dotted lines on this plot. The accompanying magnetic storm, which began also at $\approx 1600$ UT on the 13th, continued through 1800 UT on the 14th. $A_{p}$ values are shown at the top of the plot. The interval of the large amplitude, coherent diurnal oscillations, starting at $\approx 2100$ LT on the 14 th, is clearly seen. From $\approx 1200 \mathrm{LT}$ on the $17 \mathrm{th}$, when these diurnal fluctuations ended, essentially no lowfrequency motions were evident. It is also apparent 


\section{RADIAL VELOCITY RCVR I}

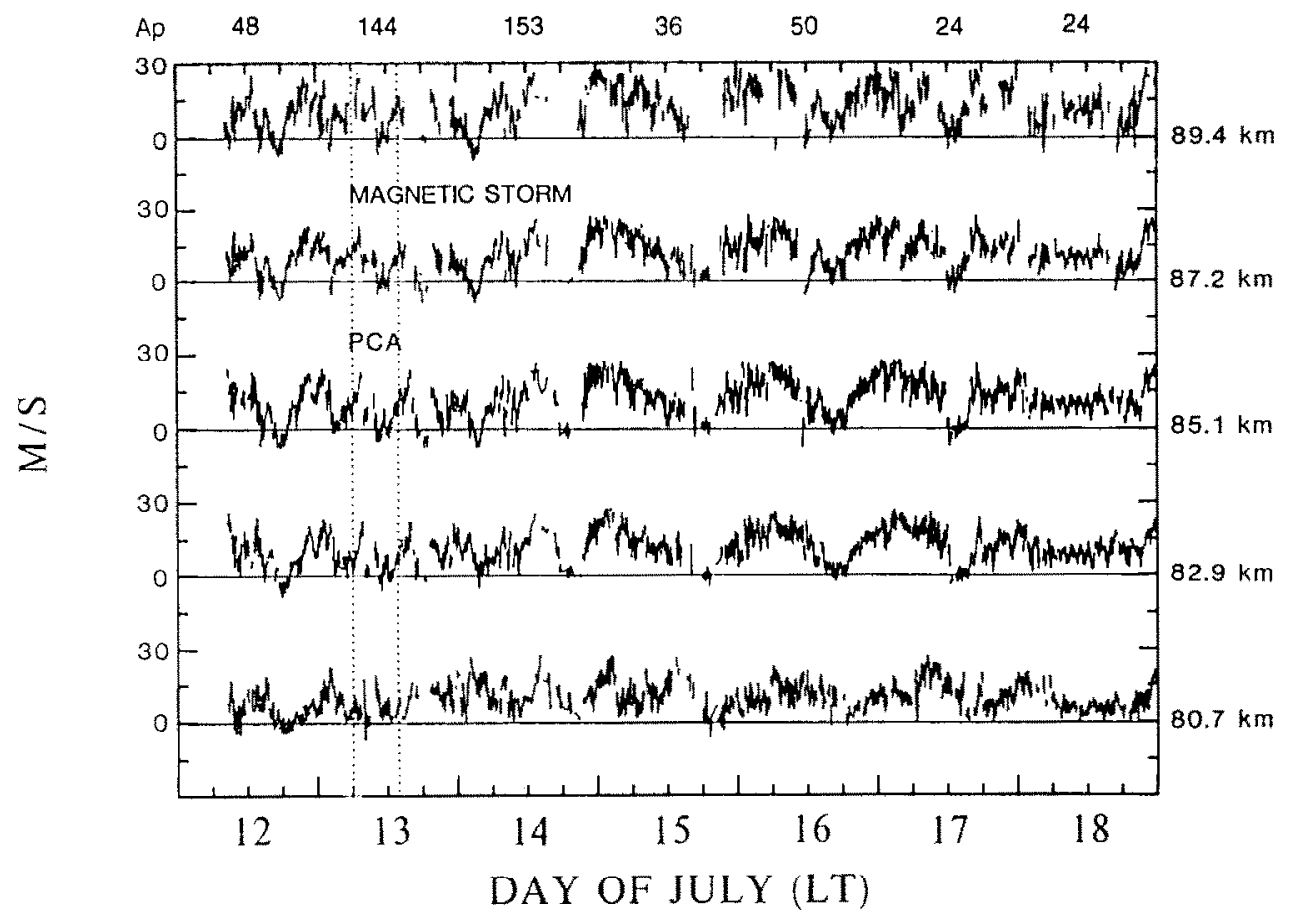

Fig. 6. Radial velocities in the $80-90 \mathrm{~km}$ range on the same oblique receiver for the $12-18 \mathrm{July} 1982$ interval. Dotted lines indicated the interval when the most intense energetic proton prccipitation occurred. The magnetic storm continued through 1800 UT on the 14 th. Local time in days is indicated along the abscissa, and $A_{p}$ is shown at the top.

that the interval of the strong diurnal oscillations was characterized by a shift in the mean wind toward the southwest. Observations on the 12th showed the presence of a scmidiurnal motion prior to the onset of the solar proton influx and magnetic storm. During the interval of the event, neither diurnal nor semidiurnal oscillations were particularly apparent; indeed, the neutral motions seemed to be dominated by higher frequency fluctuations at this time. When the radar entered the morning sector towards the end of the magnetic storm, relatively large amplitude oscillations with a frequency of $\approx 1 \mathrm{~h}$ were seen over the $80-90 \mathrm{~km}$ range. The figures that follow focus on the details of the observations described above.

In order to study the differences in the dynamical behavior of the neutrals during this interval from the 'norm', a 3 week period from 1 to 21 July was analyzed. The original data were averaged over $10 \mathrm{~min}$ intervals and then rotated into horizontal geographic coordinates. Of the original 21 days of data, 15 remained after this manipulation which were sufficiently free of gaps to allow further analysis. Any gaps present, of a duration less than $4 \mathrm{~h}$, were interpolated over. On certain days, such as the 8th, some data from the prior day were included in the fit in order to obtain a full $24 \mathrm{~h}$ interval of data. These results were summarized by grouping the data into three sets. Data obtained on the 13th to the 14th, including the interval of the SPE and magnetic storm, were grouped together. The following 3 day interval of the 15th-17th, which showed the unusual diurnal period behavior discussed above, was also considered as a subset. The remaining 10 days were grouped together, and taken to characterize 'normal' wind behavior, without influence from the geomagnetically active interval.

Figure 7 shows the altitude profile of the mean zonal and meridional velocities obtained by averaging the data in these various groups. The curves with filled boxes show the average obtained from the results of the least-squares fit to the 10 days of data taken to represent normal behavior. One-sigma standard devi- 


\section{AVERAGE VELOCITY}
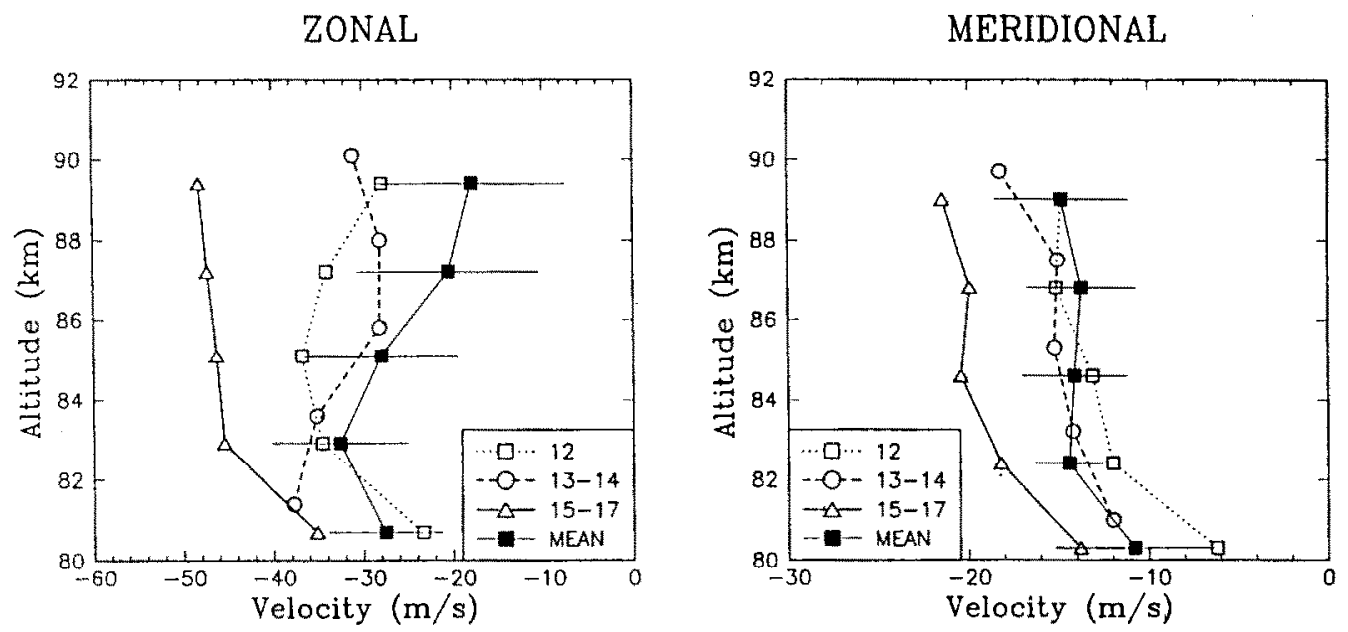

Fig. 7. Mcan zonal and meridional velocities in the $80-90 \mathrm{~km}$ altitude ranged obtained by averaging the least-square fit results together into groups. Curves with filled boxes show the average obtained from the 10 days 'undisturbed' by the SPE, and the one-sigma standard deviation of the fit results is indicated by horizontal bars. The fit results for the 12 th alone are shown with a dotted curve with open boxes. The average of the least-square fit results obtained for the 13th and the 14th is indicated with a dashed curve with open circles, while the average obtained from the 15 th-17th fits is shown with solid curves with open triangles.

ation error bars indicate the variability found for these 10 days of data. Fit results from the 12 th are shown with open boxes, the average of those from the 13th14 th interval are shown with open circles, and the open triangles show the average fit results obtained for the 15th-17th interval. During the 3-day period following the active interval, the zonal and meridional mean winds were shifted toward the west and the south by approximately twice the normal standard deviation found during the 10-day average.

The top two panels of Fig. 8 display the amplitudes of the diurnal sine wave fit for these periods relative to the mean amplitude calculated at each altitude for the 10 day 'normal' interval. Thus, in these panels, the average diurnal amplitude calculated for that interval is defined as one at each altitude. Zonal and meridional diurnal fluctuations were weaker than average for the 12th and for the interval of the 13th-14th which shows an even further reduction in amplitude. The interval of the 15 th-17th, however, shows substantially enhanced $24 \mathrm{~h}$ amplitudes in the zonal component above $85 \mathrm{~km}$, and for the meridional component below this altitude. Of course, the $24 \mathrm{~h}$ wave at upper-mesospheric heights is notorious for its variability. Even so, the zonal diurnal amplitude on the 13th and 14th was more than one-sigma less than average above $87 \mathrm{~km}$ and below $83 \mathrm{~km}$ altitude, while the amplitude during the 15 th-17th interval exceeded the average amplitude by one-sigma at the $85 \mathrm{~km}$ level. Meridional amplitudes during this time are enhanced over the norm by slightly less than one-sigma below $85 \mathrm{~km}$.

The bottom two panels in Fig. 8 display the average phase of the diurnal fluctuations for both components. The zonal mean phase structure seems consistent with a combination of evanescent and propagating components when interpreted in terms of tidal modes. The meridional average phase altitude profile shows less evidence of phase change with height. Indeed, considering the large error bars which result from the high variability of diurnal oscillations in the upper mesosphere, both components could equally well be described by purely evanescent (e.g. nonpropagating) modes. The phase structures found for the 12 th and the average of the $15 \mathrm{th}-17 \mathrm{th}$ for both the zonal and meridional components are within the onesigma standard error bars obtained for the mean curve. The altitude profile of the diurnal phase for the 13th and 14th shows more unusual behavior in both components, but particularly the zonal component. It 


\section{RELATIVE AMPLITUDE OF DIURNAL WAVE}
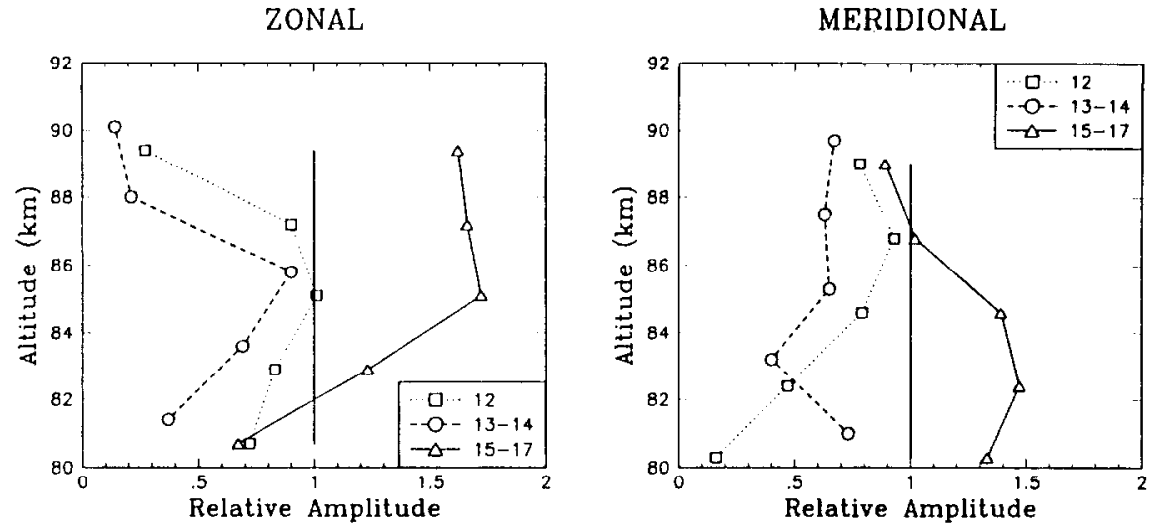

PHASE OF DIURNAL WAVE

ZONAL

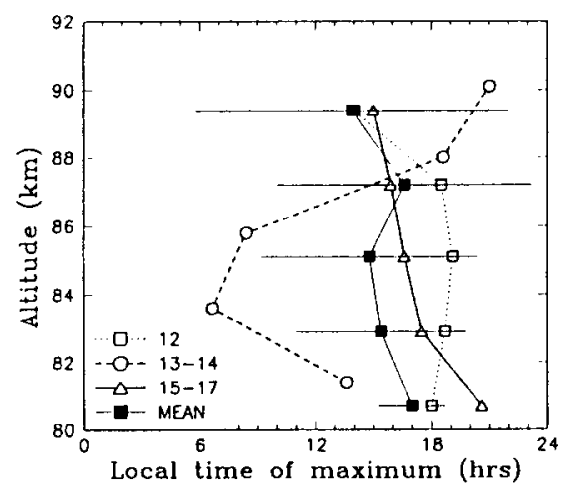

MERIDIONAL

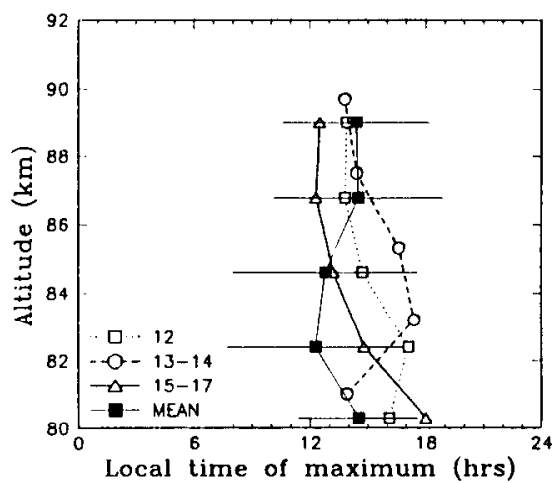

Fig. 8. Top two panels : the relative amplitude of diurnal fit results obtained by averaging the results of the least-square fits together into the same groups used in Fig. 7. The average diurnal amplitude of the 10 'undisturbed' days is defined to equal 1 at each altitude. Bottom two panels: the average phase of the diurnal fit results for the same groups. Local time of maximum eastward or northward winds is indicated along the abscissa in hours.

was during this interval, while the SPE and magnetic storm were in progress, that diurnal tidal amplitudes were the most reduced.

The diurnal phase structure for the 3-day interval was highly consistent from day-to-day. Figure 9 compares the standard deviation of the diurnal phase calculated for this 3-day interval with the mean variability in other consecutive 3-day periods of the data set. It is apparent that the diurnal phase on the 15 th17 th was roughly a factor of four less variable than is normally observed in consecutive 3-day intervals.

The relative amplitudes and phases of the semidiurnal wave fits are shown in Fig. 10, which has the same format as Fig. 8. On the 12th, the semidiurnal wave was larger than average for both components, but particularly for the meridional component. That component was nearly two-sigma greater than the average semidiurnal amplitude between 82 and $88 \mathrm{~km}$. On the 13th and 14th, the semidiurnal amplitude is reduced, particularly at the highest altitudes, by more than one-sigma from the average. For the interval of the $15 \mathrm{th}-17 \mathrm{th}$, the semidiurnal amplitude was below average for both components, with the largest reduction near $86 \mathrm{~km}$, where the reduction exceeded the one-sigma level for the zonal component.

The semidiurnal phase results are displayed in the 


\section{STANDARD DEVIATION OF DIURNAL PHASE}

\section{3-DAY INTERVALS}
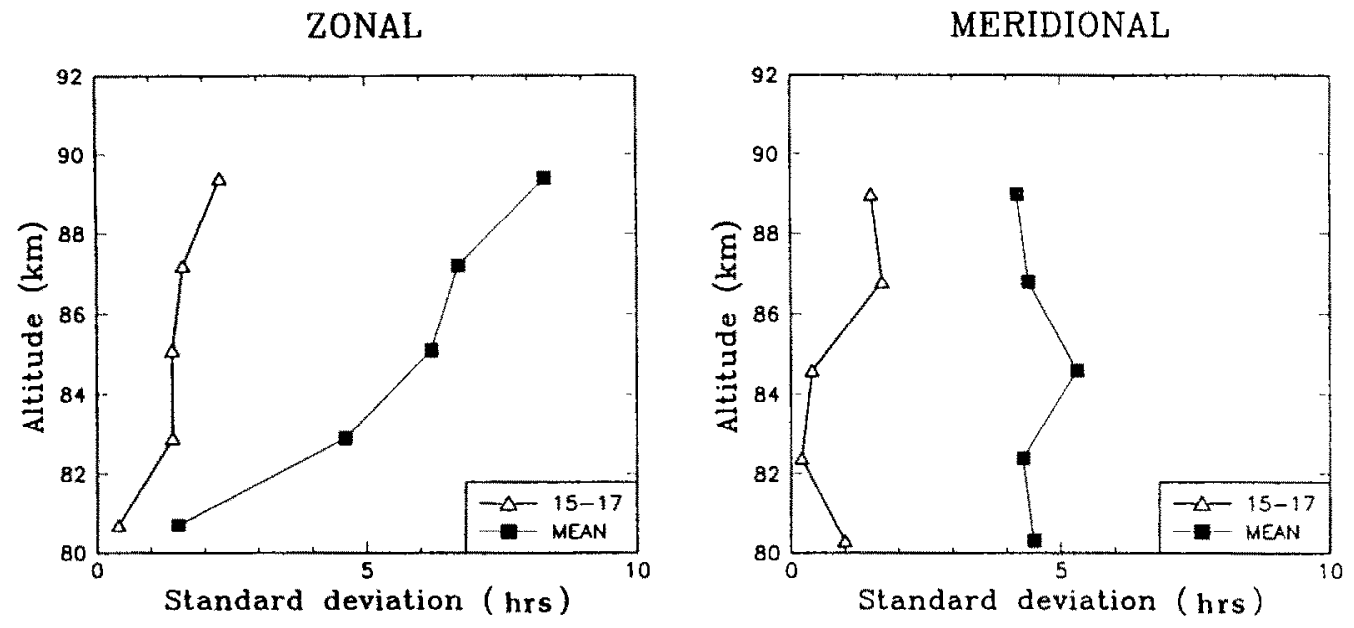

Fig. 9. Comparison of the standard deviation of the zonal and meridional diurnal phase during the 15-17 July 1982 interval with the average standard deviation calculated for other 3 day consecutive intervals of the data set.

bottom two panels of Fig. 10 in the same format as the diurnal phase results given in Fig. 8. The altitude phase structure on the $12 \mathrm{th}$ is similar to the mean of the 'undisturbed' days, particularly for the zonal component. Some phase variation with height is indicated for the mean, particularly in the zonal component. However, vertical lines could still be drawn without exceeding the one-sigma error bars. During the 13 th and 14 th, a substantial change in the phase structure occurs for the zonal component, while the meridional component shows almost no phase variation with height during this interval. From the 15 th to the 17 th, the phase seems to be consistently earlier by approximately $2 \mathrm{~h}$ than the mean for the zonal component. The meridional component also appears shifted to earlier times of local maximum, but somewhat less uniformly. When these phase profiles are interpreted in terms of tidal structure, the zonal profiles are all in general consistent with the superposition of a long wavelength mode and some higher order mode or modes. The meridional component, on the other hand, shows very little phase variation with height, except on the 12th.

In the next two figures, the presence of variable amplitude higher-frequency oscillations during the SPE and magnetic storm is indicated. Figure 11 shows the result of band-pass filtering the zonal $10 \mathrm{~min}$ averaged data from the 12th to the 18 th in the $83-87 \mathrm{~km}$ altitude range. This filter allowed waves with periods between 3 and $8 \mathrm{~h}$ to pass, but suppressed other frequencies. Compared to the interval from the 15 th to the 18 th, the preceding interval has intermediate frequency waves of larger amplitude which are seen at several different altitudes. These oscillations seem to reach their greatest amplitudes on the 13th, during the SPE. In Fig. 12, similar results are shown, but this time for a band-pass filter operating between $3 \mathrm{~h}$ and $50 \mathrm{~min}$ on the data from 85 to $89 \mathrm{~km}$. Here, the coherent high-frequency fluctuations seen on the original data plot (Fig. 6) on the 14th in the local morning sector are more apparent, and a period of about $1 \mathrm{~h}$ can be identified. Although high-frequency oscillations are certainly present during normal conditions at upper-mesospheric heights (see Fig. 5), such coherence in altitude and time is unusual. These oscillations may correspond to gravity waves produced through Joule heating and/or Lorentz forcing (LuHMaNN, 1980; WALTERSCHEID and BOUCHER, 1984).

In summary, observations of upper-mesospheric zonal and meridional neutral winds made during and after the 13 July 1982 SPE at Poker Flat show unusual behavior over a wide range of frequencies. The normal behavior of the winds in the $80-90 \mathrm{~km}$ altitude range shows a predominant semidiurnal tidal oscillation. However, higher frequency oscillations seem to be enhanced during the SPE and magnetic storm, particularly when the observing site is in the morning sector on the second day of the active interval. Diurnal 


\section{RELATIVE AMPLITUDE OF SEMIDIURNAL WAVE}
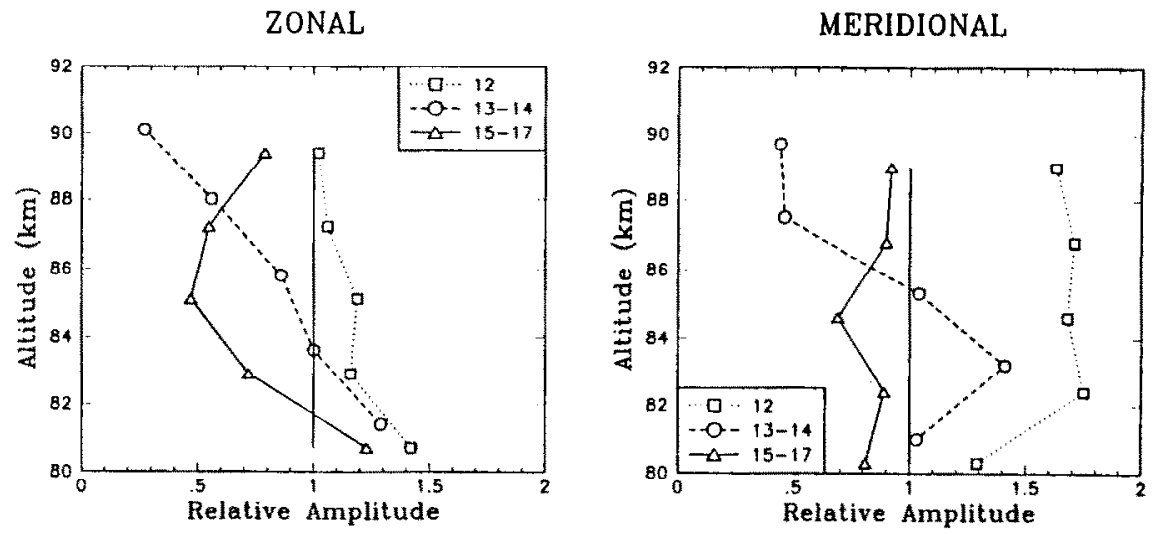

PHASE OF SEMIDIURNAL WAVE

ZONAL

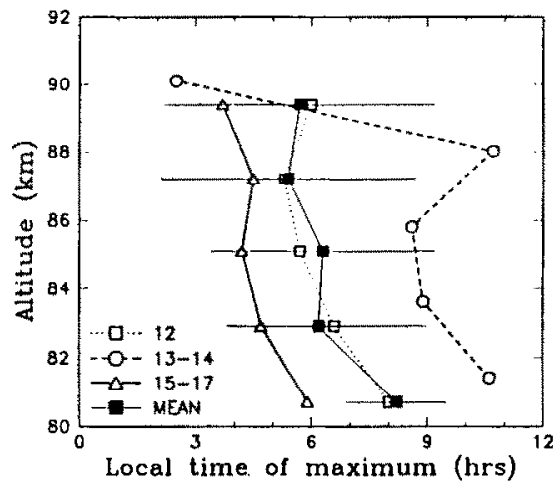

MERIDIONAL

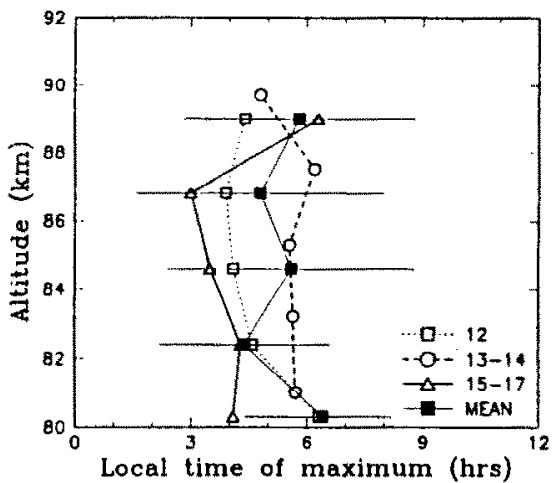

Fig. 10. Same as Fig. 8, except for the semidiumal relative amplitude (top panels) and phase (bottom panels).

oscillations, on the other hand, are particularly outstanding after the most intense magnetospheric input has ceased. The phase of the diurnal oscillations during this 3-day interval of almost monochromatic wave activity was extremely consistent.

\section{April 1984 solar proton event}

The 13 July 1982 SPE was particularly well documented and well sampled. SPEs of comparable intensity occurred roughly once every 2 yr between 1980 and 1984. Another intense SPE occurred during April 1984, while the Poker Flat MST radar was still in operation and while the upper-mesospheric echoing structure characteristic of the summer season had already started to be re-established. SME obser- vations during this event were discussed above. Energetic proton precipitation began at 1330 UT (or 0330 IT) on the 25 April and continued for several days, with maximum flux on the 26th at 1430 UT. A magnetic storm began at the same time and continued through the UT day of the $26 \mathrm{th}$. The $3-\mathrm{h} K_{p}$ values between 2300 LT on 24 April and 2300 LT on the 26th were $2,5^{+}, 5^{+}, 4^{+}, 6,6^{+}, 7^{-}, 6,6^{-}, 6,7,8^{-}, 6,5^{+}$, $5^{-}, 4^{+}$, showing that highest $K_{p}$ values were reached between 0500 and $1100 \mathrm{LT}$ on the 26th, when the precipitating energetic proton flux was most intense; however, the $K_{p}=9$ level reached during the 13 July 1982 SPE and sustained for $9 \mathrm{~h}$ was not attained.

Thus, although the magnctic storm which accompanied the April SPE was apparently not quite 


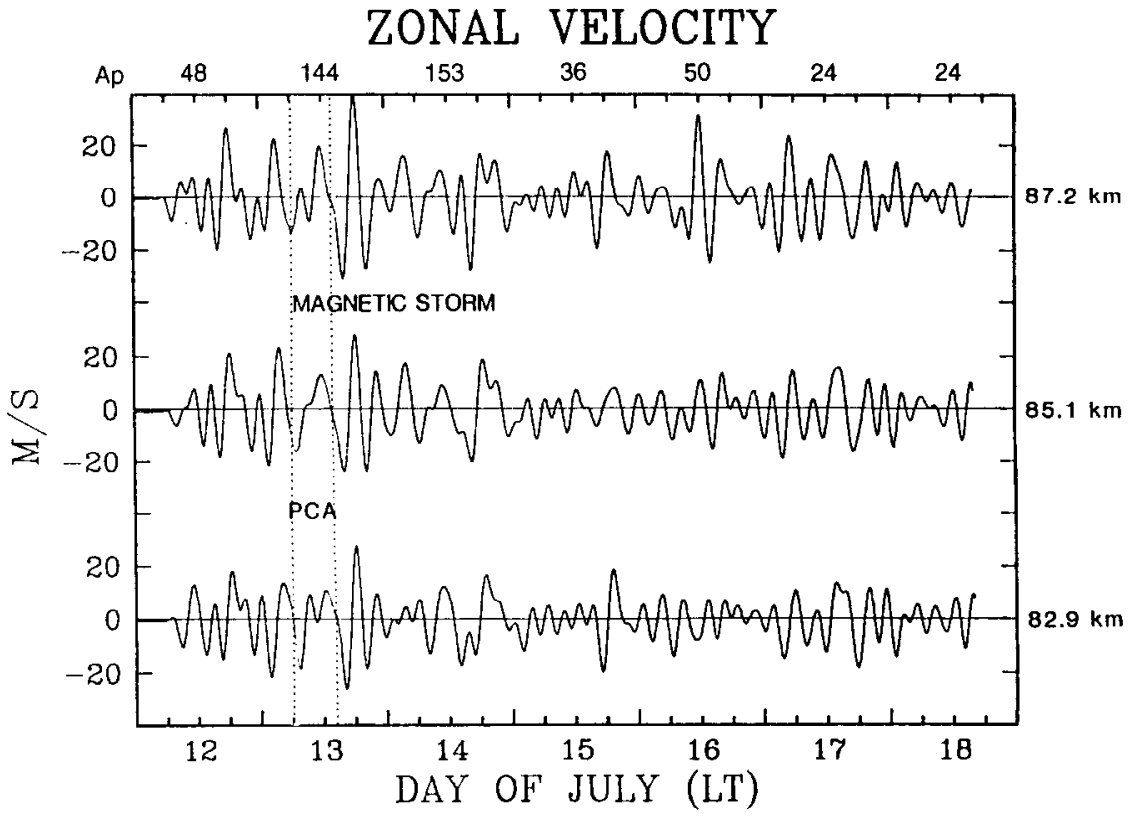

Fig. 11. Fluctuations of the zonal velocity in the $3-8 \mathrm{~h}$ range, obtained by bandpass filtering the data, during the 12-18 July 1982 interval from 83 to $87 \mathrm{~km}$. Local time in hours is indicated along the abscissa.

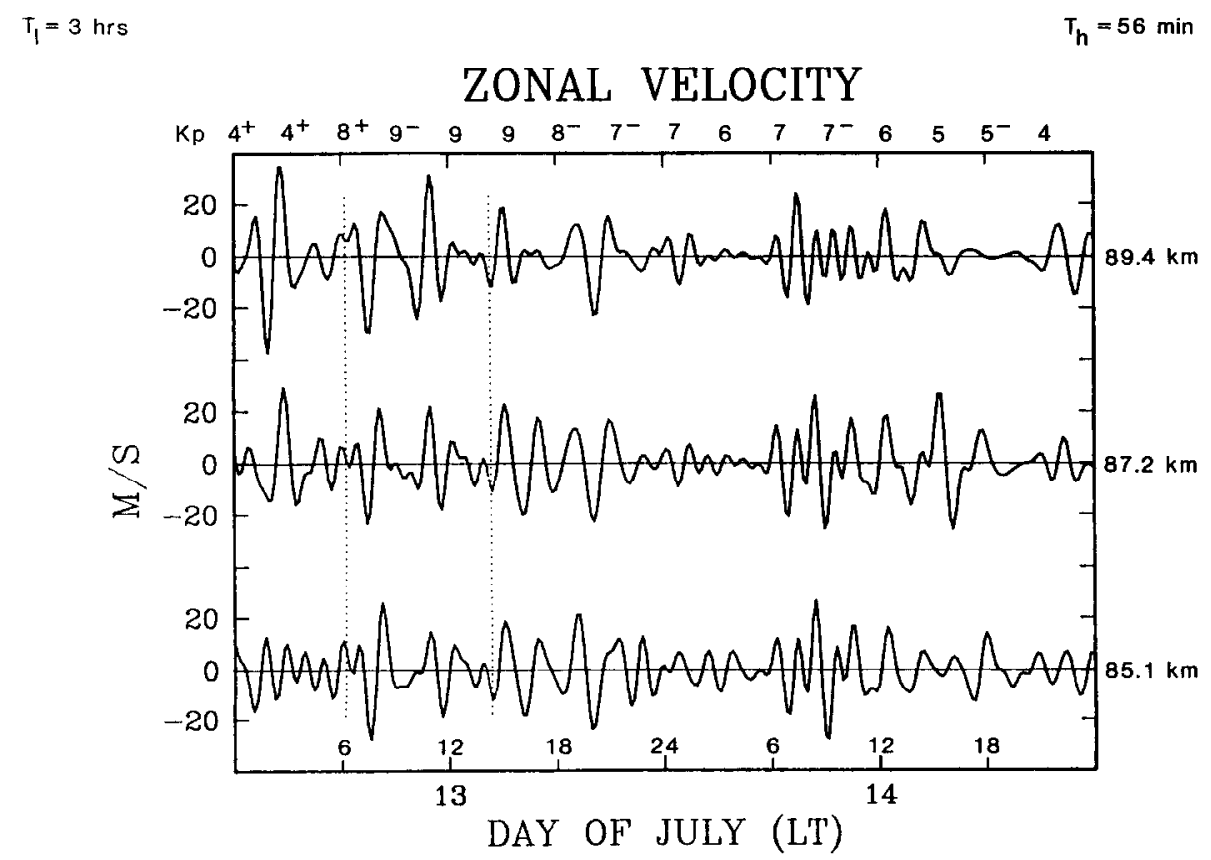

Fig. 12. Fluctuations of the zonal velocity in the $50 \mathrm{~min}-3 \mathrm{~h}$ range, obtained by bandpass filtering the data, on the 13 and 14 July 1982 . Three-hourly values of $K_{p}$ are indicated at the top of the plot. Local time in hours is indicated along the abscissa. 
as intense as that of the July 1982 event, the ozone depletion was more widespread in the polar regions and in particular reached larger values at lower heights. This in turn implies that the spectrum of the precipitating energetic protons was somewhat harder for this event. Measurements of the ionospheric electric fields are not available for the April event. However, since the $K_{p}$ values were smaller than those for the July 1982 event, the convection electric field was probably also smaller. These considerations suggest that the Joule heating which occurred during the April 1984 SPE took place at lower altitudes, and was probably somewhat less intense than during the July 1982 event. In any case, it is of interest to compare the dynamical response seen by the MST radar with that seen for the earlier event.

Figure 13 shows the radar hourly averaged radial ncutral winds observed with reccivers 1 and 2 from 22 to 28 April 1984 in the $60-70 \mathrm{~km}$ (bottom panels), $70-80 \mathrm{~km}$ (middle panels), and 80-90 km (top panels) altitude ranges. Measurements are available over a greater range of altitude for this event, than for the July 1982 event, primarily because of the variability of the MST radar echoing mechanism. Since mesospheric mean winds and tidal structures are variable with season, direct comparison of observations made during the April 1984 SPE with those made during July 1982 must be made with caution.

In Fig. 13, receiver 1 velocities are positive toward the west-southwest, while receiver 2 velocities are positive toward the south-southeast. The scale indicates the approximate magnitude of the horizontal winds, which are about a factor of 4 larger than the oblique radial velocities plotted here. Local time in days is shown along the abscissa. The interval of the magnetic storm is indicated by vertical dotted lines, and a dashed line shows the time of most intense particle precipitation.

Variations from the pre-event behavior of the neutral winds during and after the interval of intense precipitation and electric fields are evident and similar to those which were observed in conjunction with the July 1982 event, shown in Fig. 6. Below $80 \mathrm{~km}$ the enhancement in signal due to the increased ionization produced by the proton bombardment is evident. In the $65-75 \mathrm{~km}$ altitude range, receiver 1 mean velocities were generally negative, toward the east-northeast, prior to $25 \mathrm{April}$, when the particle precipitation and magnetic storm began. After the onset of magnetospheric forcing, the mean winds shifted toward the west-southwest and remained in that direction at least through 29 April. Additionally, in this altitude range, but particularly from 66.8 to $73.3 \mathrm{~km}$, the interval of shifted mean winds is also characterized by large amplitude low-frequency oscillations, apparently of a diurnal period, as was found after the 13 July 1982 SPE in the $80-90 \mathrm{~km}$ range. At greater heights, following the interval when the largest flux of energetic proton precipitation occurred, very large amplitude oscillations at some low-frequency intermediate between the diurnal and the semidiurnal period are evident, particularly in the receiver 1 observations at 84.2 and $86.4 \mathrm{~km}$. In this same altitude range, the mean winds are shifted toward the west-southwest during the interval of the magnetospheric input itself, on the 25th and the 26th. Thus, the April 1984 event gives us a second piece of evidence for a mesospheric dynamical response to SPEs in the form of enhanced diurnal oscillations and zonal mean wind shifts.

\section{DISCUSSION}

Observations at numerous stations show that oscillations at tidal frequencies near the mesopause and in the lower thermosphere vary significantly in amplitude and phase from day-to-day. The mechanisms responsible for this variability are not understood and investigation of these mechanisms is currently an active area of research. The day-to-day variability of tidal amplitudes and phases is not attributed to global changes in the tide, because this would require global changes in the thermal forcing on a similar time scalc. FORBES and GARRETT (1979) argued that the observed tidal variability may result from the natural variability in the phase of the tidal modes which compose the tidal frequency oscillations. WALTERSCHEID (1981) simulated the interaction of gravity-waves with the mean flow and showed that significant amplitude oscillations at tidal frequencies may result. The dependence of this mechanism on gravity-wave parameters, which are expected to be quite variable from day-today, has been invoked to associate the mechanism with the day-to-day variability of tidal amplitudes and phases. Teirelbaum et al. (1989) investigated the nonlinear interaction between 24 and $12 \mathrm{~h}$ tides, and showed that secondary terdiurnal and diurnal waves with non-negligible amplitudes may be induced at mid to high latitudes. Teitelbaum and VIAL (1991) studied the nonlinear interaction of tides and planetary waves and showed that the induced secondary waves beat with the tide to produce a tidal amplitude modulation with the planetary wave period. This latter mechanism was shown to be consistent with wind measurements during several campaigns at Garchy $\left(45^{\circ} \mathrm{N}\right)$.

The observations discussed in the preceding sections have shown the presence of an extremely consistent diurnal oscillation lasting for 3 days after an 
April, 1984 SPE Neutral Winds
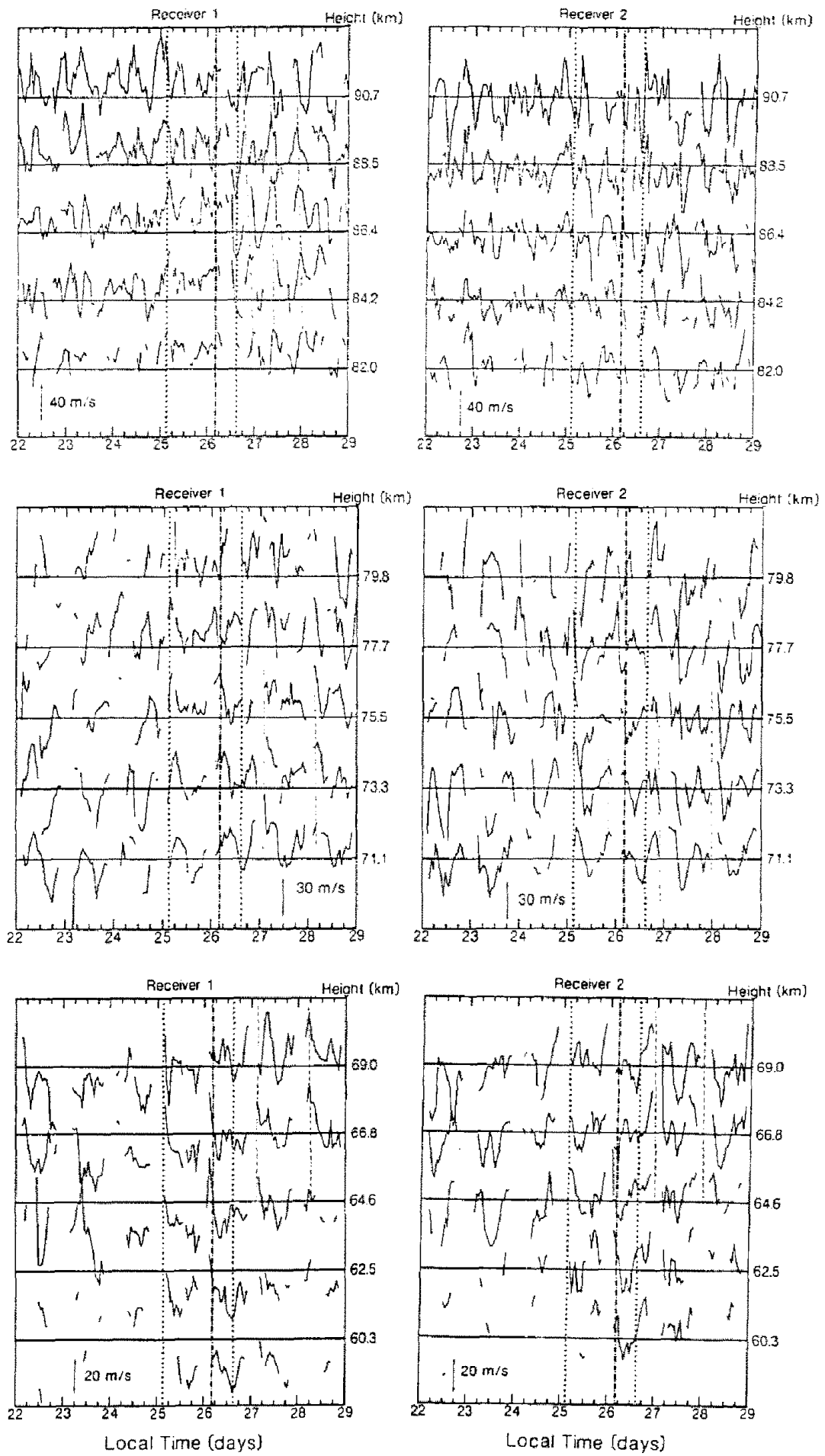

Fig. 13. Poker Flat, MST hourly averaged oblique radial velocities on receiver 1 (left) and 2 (right) from 60 to $90 \mathrm{~km}$ for the interval of $22-28$ April 1984 . Intervals of maximum magnetospheric input are indicated. Receiver 1 velocities are positive toward the west-southwest, while receiver 2 velocities are positive toward the south - southeast. Note the progressively large vertical scales used in the three panels as altitude increases. 
interval of intense magnetospheric forcing of the lower thermosphere and the upper mesosphere on 13 July 1982. A similar oscillation was observed following the April 1984 event. The fact that this unusual behavior lasted for a period as long as 3 days suggests that it resulted not from the mechanisms which produce the normal day-to-day variability indicated in Fig. 5, but instead from some mechanism capable of generating a quasi-steady 'tidal' field. This mechanism must account for rapid and long lasting reductions in $12 \mathrm{~h}$ amplitudes and quasi-steady large amplitude diurnal oscillations, as well as for intervals when neither of these low frequency waves are apparent. These requirements seem to rule out the possibility of a gravity-wave-mean flow interaction mechanism because of the expected variability of this source.

The observed mesospheric ozone depletion and Joule heating described above certainly produced sudden changes in the neutral heating rate during the 13 July 1982 SPE. The results of REAGAN et al. (1981) suggest that even though the mesospheric ozone depletion lasts only a relatively short period of time, it produces a longer-term decrease in the neutral heating rate. This in turn causes a reduction of mesospheric temperatures that lasts for several days after the fairly short-lived cvent. The Joulc heating, on the other hand, produces a sudden increase in the neutral heating rate in the upper-mesosphere.

Calculations using a steady-state classical tidal model and rough approximations to the heating rates consistent with the observed maximum Joule heating and ozone depletion show that significant differences in tidal amplitudes may result (JoHNSON, 1987). Model results indicate enhanced diurnal tidal amplitudes when a heat source is added in the $80-120 \mathrm{~km}$ altitude range. This agrees with the observations, where large amplitude evanescent diurnal oscillations were observed following the SPEs considered here. However, these calculations did not address the temporal development of the forcing and winds during and following the event and can therefore only be used as a rough indication that some upper mesospheric dynamical response may be expected.

The time required to set up an evanescent diurnal tidal oscillation corresponds approximately to the time required for the initial transient motions to propagate through the latitudinal extent of the forcing region, of the order of several hours to a day (Walterscheid, pers. commun.). The results of REAGAN et al. (1981) have shown that a sudden change in the ozone distribution at high latitudes during an SPE can produce a relatively long-lasting change in the heating rate profile, of the order of a week. Following a sudden reduction in the mesospheric heating rate at high latitude due to ozone depletion and a sudden increase in the heating rate in the upper mesosphere and lower mesosphere due to Joule dissipation, a striking change in the tidal behavior of the neutral winds was observed approximately a day later, which lasted for approximately 3 days thereafter. In particular, an increase of the diurnal zonal and meridional amplitudes was observed, along with a decrease in the semidiurnal tidal fluctuations. These observations are consistent with the model predictions (JOHNSON, 1987), based on assuming a steady-state heating rate profile which approximates the maximum effects of the ozone depletion and Joule heating observed during the peak of the SPE. Alternatively, the addition of a Joule heat source alone would produce enhanced diurnal amplitudes, regardless of the ozone depletion effects.

Finally, the interaction of a planetary wave with the tidal field may be related to the observed wind variations. Teitelbaum and Vial (1991) showed that this mechanism could produce modulations of diurnal or semidiurnal amplitudes with the period of the planetary wave oscillation, resulting in intervals of slowly changing tidal amplitude and periods of very small tidal amplitudes. Such a mechanism may be involved here, but in this case modulations in both diurnal and semidiurnal amplitudes are seen. Indeed, investigation of Fig. 5 shows that following the 13 July 1982 SPE there is some regularity in the low frequency wave form through the rest of July: large amplitude, neardiurnal oscillations are observed on 15-17 July and there is considerable power near the diurnal frequency on 21-23 July, on the 18th and on the latter half of 24-25 July little power is apparent at low frequency, and on 19 and $20 \mathrm{July}$, the semidiurnal dominates again. On 26-28 July, power seems to be significant in both the 12 and $24 \mathrm{~h}$ components. Overall, there is some indication of a 6-day periodicity in the wind variations following the SPE. This periodicity is not apparent prior to the SPE, although this statement must be qualified because of the multi-day data gap just prior to the event.

The shift in the mean wind direction following the SPEs to the southwest is consistent with some observations of changes in the mean winds at greater heights during intervals of geomagnetic activity. The Coriolis acceleration acting on a net equatorward flow from the northern polar regions, produced by highlatitude heating (RoBle et al., 1977; Richmond, 1979), would produce a westward component in the mean zonal wind. WAND (1983) has postulated that the enhanced south-westward winds observed with the Millstone Hill incoherent scatter radar $\left(42^{\circ} \mathrm{N}\right)$ in the $115-135 \mathrm{~km}$ altitude range during intervals of 
geomagnetic activity are part of this activity-produced thermospheric meridional circulation cell. The observations presented here, at mesospheric heights, may reflect the extension of this circulation cell to much lower altitudes than normal due to the extreme level of magnetospheric forcing which characterizes these SPES.

\section{CONCLUSIONS}

During and following the 13 July 1982 SPE, unusual neutral wind oscillations occurred over a wide range of frequencies at upper-mesospheric heights in observations obtained by Poker Flat, MST radar. This event, which was particularly well documented, was accompanied by a significant ozone depletion in the high-latitude upper mesosphere, as well as by intense Joule heating at these heights. Analysis of the tidal oscillations during and following the event showed particularly enhanced and long-lasting evanescent diurnal tidal oscillations to the virtual exclusion of other low-frequency motions. During this period, the mean wind shifted to the west-southwest by 5 $30 \mathrm{~m} / \mathrm{s}$ over the $81-90 \mathrm{~km}$ altitude range, or by approximately twice the normal standard deviation. In addition, high-frequency fluctuations were apparently enhanced during the most intense interval of magnetospheric forcing.

A second SPE, on 26 April 1984, was also analyzed. Mean flows were observed to increase towards the west-southwest following the SPE, and to remain enhanced for several days afterwards. Additionally, an increase in the amplitude of apparently diurnal oscillations was noted although the altitude at which this was most apparent differed from the case of the 13 July 1982 event. Direct comparison of the observations made during the two SPEs is difficult because the observations were made during different seasons of the year. As a result, measurements were obtained from a different altitude range, such that the normal mean wind and tidal behavior could be expected to differ. In addition, the altitude of maximum ionization also differed in the two SPEs, as was discussed above, and therefore the altitude difference in its related effects is not unreasonable.

Potential mechanisms responsible for the changes in the amplitudes and phases of diurnal and semidiurnal wind oscillations following the two SPEs studied here have been discussed. Changes in the contributions of tidal modes due to variations in the tidal heating rates arising from altered Joule heating and/or ozone depletion may be involved (JoHNSON, 1987). However, it then becomes difficult to explain the temporal development of the winds relative to the variations in thermal forcing expected to be produced by the SPEs. Alternatively, simulations of the interaction of planetary waves with diurnal or semidiurnal waves (Teirelbaum and Vial, 1989) have had some success at reproducing observations of slowly varying tidal amplitudes and periods of very low amplitude oscillations. These observations are somewhat similar to those analyzed in this study, although unusual behavior is noted here at both the diurnal and semidiurnal frequencies.

Resolution of which mechanisms are responsible for the unusual wave and mean flow variations following the 13 July 1982 and 26 April 1984 SPEs will require further efforts at simulations of these events. These studies should include the effects of time-varying ozone depletion and enhanced mesospheric and lower thermospheric Joule heating. In addition, the effects of planetary waves on both diurnal and semidiurnal tides should be further investigated to determine if the variations in tidal amplitudes observed following these SPEs can be explained on the basis of this mechanism.

Acknowledgements-This study was funded through NSF grant ATM 85-15627, while the first author was a student at the University of California at Los Angeles, and was completed with funding from NSF grant ATM 90-96134. The authors thank Dr B. Balsley, who provided the radar data analyzed in this study, $\mathrm{Dr} \mathrm{R}$. Walterscheid, who provided his classical tidal model for this effort, and $\mathrm{Dr}$ R. Thomas, who provided unpublished SME data.

\section{REFERFNCES}

\section{Balsley B. B., Ecklund W. L. and Fritts D. C.}

BANKS P. M.

BERNARD R.

Carter D. A. and Balsley B. B.

Crutzen P. J. and SOlomon S.

Fellous J. L., Bernard R., Glass M.,

Massebeuf M. and Spizzichino A.

Forbes J. M. and GarretT H. B.

Forbes J. M. and Garrett H. B.
1984

1979

1981

1982

1980

1975

1978

1979
In Dynamics of the Middle Atmosphere, J. J. HoLTON and T. Matsuno (eds), p. 77. Terra Scientific Publishing Co.

J. geophys. Res. 84, 6709.

J. atmos. terr. Phys. 43, 663.

J. atmos. Sci. 39, 2905.

Planet. Space Sci. 28, 1147.

J. atmos. terr. Phys. 37, 1511.

Geophys. Res. Lett. 5, 1013.

Rev. Geophys. Space Phys. 17, 1951. 
FREDERICK J. E.

Holton J. R.

JOHNSON R. M.

JoHNSON R. M. and LUHMANN J. G.

JOHNSON R. M. and LUHMANN J. G.

JOHNSON R. M. and VIRDI 'I'. S.

Killeen T. L., Nardi B., Purcell P. N.,

Roble R. G., Fuller-Rowell T. J. and Rees D.

LuHMANN J. G.

MAEDA K. and AIKIN A. C.

Manson A. H. and MeEK C. E.

Manson A. H., Meek C. E., Gregory J. B. and Chakrabarty D. K.

MCPeters R. D. and Jackman C. H.

PARK J. G. and London J.

PRICE G. D. and JACKA F.

Price G. D., Jacka F., VinCent R. A. and Burns G. B.

Reagan J. B., Meyerott R. E., Nightingale R. W., Gunton R. C., Johnson R. G., Evans J. E.,

ImhoF W. L., Heath D. F. and KRueger A. J.

RiChMOND A. D.

Roble R. G., Dickinson R. E. and Ridley E. C.

Roble R. G., EMEry B. A., Killeen T. L.,

Reid G. C., Solomon S., Garcia R. R.,

Evans D. S., Hays P. B., CaRignan G. R.,

Heelis R. A., Hanson W. B., Winningham D. J.,

SPENCER N. W. and BraCe L. H.

SOlomon S., Rusch D. W., GÉrard J.-C.,

Reid G. C. and Crutzen P. J.

Teitelbaum $H$. and Vial $F$.

Teitelbaum H., Vial F., Manson A. H.,

Giraldez R. and Massebeuf $M$.

Thomas R. J., Barth C. A., Rottman G. J.,

Rusch D. W., Mount G. H., Lawrence G. M.,

Sanders R. W., Thomas G. E. and Clemens L. E.

THORNE R. M.

WALTERSCHEID R. L.

WALTERSCHEID R. L. and BOUCHER D. J. JR

WAND R. H.
$1976 \quad$ J. geophys. Res. 81, 3179.

1975 The Dynamic Meteorology of the Stratosphere and Mesosphere. American Meteorological Society, Lancaster Press, Lancaster, Pennsylvania.

1987 Ph.D. thesis. Department of Earth and Space Science, University of California at Los Angeles.

$1985 \quad J$.geophys. Res. 90, 1735.

$1988 \quad J$. geophys. Res. 93, 8625.

1991 J.geophys. Res. 96, 1099.

1992 Geophys. Res. Lett. 19, 1093.

$1980 \quad$ J. geophys. Res. 85, 1749.

1968 Planet. Space Sci. 16, 371.

1986 Ann. Geophys. 4, 281.

1982 Planet. Space Sci. 30, 1283.

1985 J. geophys. Res. 90, 7945.

1974 J. atmos. Sci. 31, 1898.

1991 J. atmos. terr. Phys. 53, 10,909.

1991 J. atmos. terr. Phys. 53, 10,923.

$1981 \quad J$. geophys. Res. 86, 1473.

1979 J.geophys. Res. 84, 5259.

1977 J. geophys. Res. 82, 5493.

1987 J.geophys. Res. 92, 6083.

1981

Planet. Space Sci. 29, 885.

1991 J.geophys. Res. 96, 14,169.

1989 J. atmos. terr. Phys. 51, 627.

1983 Geophys. Res. Lett. 10, 253.

$1980 \quad$ Pageoph 118, 128.

$1981 \quad$ J.geophys. Res. 86, 9698.

1984 J.atmos. Sci.41, 1062.

1983 J. geophys. Res. 88, 9243. 